\title{
A critical review of the development, current hotspots, and future directions of Lake Taihu research from the bibliometrics perspective
}

\author{
Yunlin Zhang ${ }^{1} \cdot$ Xiaolong Yao ${ }^{1,2} \cdot$ Boqiang Qin ${ }^{1}$
}

Received: 16 April 2016 / Accepted: 9 May 2016 /Published online: 18 May 2016

(C) Springer-Verlag Berlin Heidelberg 2016

\begin{abstract}
Lake Taihu, as the important drinking water source of the Yangtze River Delta urban agglomeration and the third largest freshwater lake in China, has experienced serious lake eutrophication and water quality deterioration in the past three decades. Growing scientific, political, and public attention has been given to the water quality of Lake Taihu. This study aimed to conduct a comparative quantitative and qualitative analysis of the development, current hotspots, and future directions of Lake Taihu research using a bibliometric analysis of eight well-studied lakes (Lake Taihu, Lake Baikal, Lake Biwa, Lake Erie, Lake Michigan, Lake Ontario, Lake Superior and Lake Victoria) around the world based on the Science Citation Index (SCI) database. A total of 1582 papers discussing Lake Taihu research were published in 322 journals in the past three decades. However, the first paper about Lake Taihu research was not found in the SCI database until 1989, and there were only zero, one, or two papers each year from 1989 to 1995. There had been rapid development in Lake Taihu research since 1996 and a sharp increase in papers since 2005. A keyword analysis showed that "sediment," "eutrophication", "Microcystis aeruginosa", "cyanobacterial blooms", and "remote sensing" were the most frequently used keywords of the study subject. Owing to its significant impact
\end{abstract}

Responsible editor: Philippe Garrigues

Yunlin Zhang

ylzhang@niglas.ac.cn

1 Taihu Laboratory for Lake Ecosystem Research, State Key Laboratory of Lake Science and Environment, Nanjing Institute of Geography and Limnology, Chinese Academy of Sciences, Nanjing 210008, P. R. China

2 University of Chinese Academy of Sciences, Beijing 100049, P. R. China on aquatic ecosystems, a crucial emphasis has been placed on climate change recently. In addition, the future focuses of research directions, including (1) environmental effects of physical processes; (2) nutrient cycles and control and ecosystem responses; (3) cyanobacteria bloom monitoring, causes, forecast and management; (4) eutrophication and climate change interactions; and (5) ecosystem degradation mechanism and ecological practice of lake restoration, are presented based on the keyword analysis. Through multidisciplinary fields (physics, chemistry, and biology) cross and synthesis study of Lake Taihu, the development of shallow lake limnology will be largely promoted.

Keywords Author keyword - Bibliometric analysis · Current hotspots · Future directions · Lake Taihu $\cdot$ Web of Science

\section{Introduction}

Lake Taihu Basin has an area of $36,895 \mathrm{~km}^{2}$ and accounts for $0.4 \%$ of China's territory (Qin et al. 2007). However, in 2014, Lake Taihu Basin accounted for 4.4 and $9.9 \%$ of the total population and gross domestic product (GDP), respectively, of this country (TBA-MWR 2015). Therefore, Lake Taihu Basin is the one of the most developed regions of industrialization, urbanization, and agricultural intensification and plays a vital role in China's social and economic development. As the core of Lake Taihu Basin, Lake Taihu serves several important ecological service functions, including the drinking water supply, flood control, tourism and recreation, shipping and aquaculture (Qin et al. 2007). Specifically, Lake Taihu is the drinking water source for several large cities and megalopolises, such as Shanghai, Suzhou, Wuxi, and Huzhou. Since the 1980s, however, rapid economic development of Lake Taihu Basin has resulted in a large amount of 
industrial, agricultural, and residential pollutants discharged into the rivers and lake (Qin et al. 2007). With the deterioration of water quality, eutrophication and cyanobacterial blooms (Microcystis aeruginosa) have frequently occurred, resulting in a significant decrease in ecological service functions. In particular, in late May 2007, massive cyanobacterial blooms accumulated around the drinking water source of Wuxi City, China, and cut off drinking water supplies to approximately 2 million local residents for 1 week (Qin et al. 2010, Yang et al. 2008, Zhang et al. 2010b). The 2007 Wuxi Water Crisis was a particularly serious environment pollution event that was even discussed in a World Bank report (The World Bank 2010).

Currently, eco-environmental issues of Lake Taihu have attracted the world's attention and have been research hotspots for scientists around the world (Guo 2007, Yang et al. 2008). In addition, Lake Taihu research has been a multidisciplinary field covering limnology (Xu et al. 2010), environmental sciences (Xu et al. 2014), marine freshwater biology (Qin et al. 2007), water resources (Zhang et al. 2009), ecology (Qin 2009a), remote sensing (Shi et al. 2015), and others. Previously, several reviews discussed the main ecoenvironmental problems of the lake, such as nutrient enrichment and cycle mechanisms; the dynamics of harmful cyanobacterial bloom formation, forecasts, and early warnings; and the formation mechanism of black water aggregation from different research perspectives (Fan 2015, Kong et al. 2009, Qin 2009b). However, due to the differences in the different study directions and the limited literature included, it is still difficult to provide a comprehensive understanding of the focus of past research and the present research situation of Lake Taihu. It is impossible to summarize the future research directions from a single subject or research topic perspective.

Bibliometrics, which was first introduced by Pritchard (1969), has been widely used to quantitatively and qualitatively analyze scientific production and research trends at the decade to century scale with a large amount of data (Zhi et al. 2015). Using the Science Citation Index-Expanded (SCI-Expanded) database of Web of Science and "bibliometric analysis" as the topic, 1213 papers covering 109 subject categories could be searched by the end of 2015 . For example, in environmental science, this method has been used to study wetland (Zhang et al. 2010a, Zhi and Ji 2012), global climate change ( $\mathrm{Li}$ et al. 2011, Pasgaard and Strange 2013), carbon cycling (Zhi et al. 2015), phosphorus research in eutrophic lakes (Gao et al. 2015), and other subjects. In summary, bibliometric analysis is focused on certain study subjects in most cases but is seldom focused on a certain study region (Wang et al. 2015).

The SCI-Expanded database is the most comprehensive and frequently used data source in bibliometrics for reviewing high-quality publications and for assessing scientific development, current hotspots, and future directions (Barbosa and
Schneck 2015, Khan and Ho 2012, Zhi and Ji 2012). For example, more than $80 \%$ of papers used the SCI-Expanded database as the data source when we searched bibliometric analysis as the topic in the SCI-Expanded database by the end of 2015. In addition, author keywords generally represent the essence of a published paper and therefore have been widely used to assess research hotspots within a specific field and to suggest future science directions (Tan et al. 2014).

Therefore, in this study, we conducted a comparative quantitative and qualitative analysis of the development, current hotspots, and future directions of Lake Taihu research using a bibliometric analysis of eight well-studied lakes (Lake Taihu, Lake Baikal, Lake Biwa, Lake Erie, Lake Michigan, Lake Ontario, Lake Superior, and Lake Victoria). More specifically, the aims of this study are as follows: (1) to summarize the variation characteristics of total publication output, document type, and language of publications; the distribution of output in subject categories and journals; and the publication outputs of country, institution, and author; (2) to reveal the current hotspots of Lake Taihu research and compare them with those of other hot lakes around the world based on the keyword analysis; and (3) to discuss the future directions, which may serve as a potential guide for future research.

\section{Data and methods}

\section{Data}

The data were based on the online version of the SCIExpanded database, Web of Science. The SCI is a multidisciplinary database of the Institute for Scientific Information (ISI), Philadelphia, PA, USA. According to Journal Citation Reports (JCR), the SCI-Expanded database includes 11,149 major journals that have citation references across 237 scientific disciplines and that were distributed in 82 countries as of 2015. Since 1991, abstracts have been added to each SCI publication. For bibliometric analysis, the online version of SCI-Expanded was searched using the keywords (TS = "Lake Taihu" or "Taihu Lake") as the topic to compile a bibliography of all papers related to Lake Taihu research from 1900 to 2015. In addition, we searched the hot lakes of limnology study from SCI-Expanded database in order to compare the increase trend of total publication number of Lake Taihu with other hot lakes around the world. Overall, Lake Baikal, Lake Biwa, Lake Erie, Lake Michigan, Lake Ontario, Lake Superior, and Lake Victoria were widely reported in the SCI-Expanded database. Therefore, the keywords (TS = "Lake Baikal" or "Baikal Lake"; TS = "Lake Biwa" or "Biwa Lake"; TS = "Lake Erie" or "Erie Lake"; TS ="Lake Michigan" or "Michigan Lake"; TS = "Lake Ontario" or "Ontario Lake"; TS = "Lake Superior" or "Superior Lake"; $\mathrm{TS}=$ "Lake Victoria" or "Victoria Lake") were searched as 
the topic to compile a bibliography of all papers related to the research on Lake Baikal, Lake Biwa, Lake Erie, Lake Michigan, Lake Ontario, Lake Superior, and Lake Victoria from 1900 to 2015 .

Document information included author(s), title, source (journal title), language, country, document type, author keywords, addresses, and subject category. Full records were downloaded into Microsoft Excel 2013 for further analysis. The journal impact factor (IF) was obtained from JCR Science Edition 2015. Country and institution contributions were estimated by the affiliation location of at least one author of the published paper. Articles from Hong Kong (HK) and Taiwan (TW) were excluded with articles from China.

\section{Analysis method}

Keywords contain the most critical information in most papers. Thus, the frequency analysis of keywords was used to discover the most interesting Lake Taihu research topics and methodologies. Notably, only author keywords, not KeyWords Plus, were used for this analysis.

\section{Statistical analysis}

Statistical analyses, including calculations of the average, maximum, and minimum values and linear and non-linear regressions, were performed using Statistical Program for Social Sciences (SPSS) 17.0 software. We performed correlation analyses using SPSS software to investigate the relationships between the variables. The differences in the parameters were assessed by one-way ANOVA $(p<0.05)$. The significance levels were reported as significant $(p<0.05)$ or nonsignificant $(p>0.05)$.

\section{Results and discussion}

\section{Variation characteristics of total publication number}

The total publication number (TPN) was 1582 when the aforementioned search strategy was used. However, the first paper about Lake Taihu research was not found in the SCIExpanded database until 1989. In contrast, the first paper about Lake Baikal, Lake Biwa, Lake Erie, Lake Michigan, Lake Ontario, Lake Superior, and Lake Victoria research was found in 1901, 1971, 1906, 1900, 1913, 1900, and 1905 , respectively. Therefore, it is not difficult to conclude that Lake Taihu research is largely far behind that of many hot lakes around the world. Because there were only zero, one, or two papers about Lake Taihu research each year from 1989 to 1995 , we focused our bibliometric analysis on the past 20 years, from 1996 to 2015 . A total of 1575 publications were identified from 1996 to 2015; there has been a sharp increase in publications since 2005 (Fig. 1). The corresponding total publication number was 1930, 750, 1788, 2263, 1727, 1369, and 1466 from 1996 to 2015, for Lake Baikal, Lake Biwa, Lake Erie, Lake Michigan, Lake Ontario, Lake Superior, and Lake Victoria, respectively. In most cases, the total publication number of Lake Taihu is less than that of the other hot lakes. However, it must be noted that the increase speed of the total publication number for Lake Taihu is much faster than that of any other hot lakes (Fig. 1). The exponential increase in the rate of total publication number vs year for Lake Taihu is 0.268 , which is 3-14 times that of other hot lakes (Table 1). The cumulative publication number of Lake Taihu from 2006 to 2015 is higher than that of other hot lakes, and the publication number of 301 for Lake Taihu in 2015 is much higher than 135, 43, 120, 152, 94, 86, and 132 for Lake Baikal, Lake Biwa, Lake Erie, Lake Michigan, Lake Ontario, Lake Superior, and Lake Victoria, respectively. Therefore, Lake Taihu is currently the hottest lake of limnology studies around the world.

\section{Document type and language of publication}

Of 1575 publications that were identified from 1996 to 2015, 8 document types were identified, and peerreviewed journal article was the most common article type (1542 or $97.90 \%$ of all publications). Likewise, proceeding paper $(52 ; 3.30 \%)$ and reviews (15; $0.95 \%$ ) composed a small portion of the obtained publications. Other document types included meeting abstracts (8), editorial materials (5), letters (2), corrections (2), and news items (1). The numbers that are enclosed in parentheses indicate the number of papers that were found for each document type. Because journal articles constitute the majority of document types and contain original work by scientists around the world, only 1542 original and peer-reviewed articles were used below for further analysis.

A total of 1509 or $97.86 \%$ of these journal articles were written in English. This result shows that English is the absolute dominant academic language and that most SCI-indexed journals are published in English. In addition, 32 other publications were written in Chinese, and 1 publication was written in Portuguese.

\section{Publication patterns: subject categories and journals}

The ISI grouped the subjects of these publications into 55 categories over the past 20 years. Table 2 shows the publication distribution of the 20 most common subject categories about Lake Taihu research. "Environmental Sciences Ecology," "Marine Freshwater Biology," and "Engineering" are the top three most popular subject categories. 
Fig. 1 Increase in total publication number (a) and cumulative total publication number (b) of eight hot lakes (Lake Baikal, Lake Biwa, Lake Erie, Lake Michigan, Lake Ontario, Lake Superior, Lake Victoria, and Lake Taihu) from 1996 to 2015
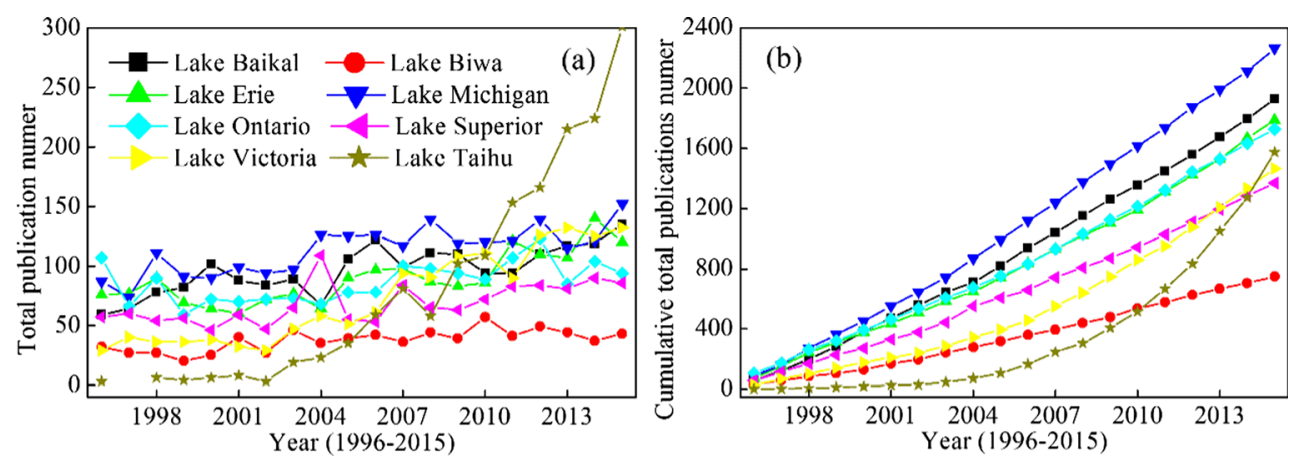

A total of 1542 publications about Lake Taihu research were published in 317 different journals. Table 3 shows the publication distribution of the 20 most common journals, which accounted for $42.3 \%$ of the total publications. Journal of Environmental Sciences China, Hydrobiologia, and Environmental Science and Pollution Research are the top 3 journals, with the publication of more than 50 papers for each journal. In addition, Table 3 shows the SCI category of the journal, the position of the journal in its category, IF, and the h-index of the top 20 productive journals. The IF is widely used to evaluate a journal's relative importance, especially when compared to others in the same field. Since the hindex was first proposed by Hirsch (2005), it has been widely used to characterize both the quantity and significance of a scientist's research publication.

\section{Publication performances: country, institutes, and author}

We generated the data on the country and institutional distribution of publications based on the author affiliation information. Undoubtedly, the most productive country in terms of the number of total publications for single country articles and international collaborations is China, accounting for $96.7 \%$. However, we also noted that many famous scientists from USA, Australia, and Canada performed related research at Lake Taihu. Paerl HW, Wilhelm SW, and Otten TG had the first author article about Lake Taihu, which partially reflected that Lake Taihu research has gained worldwide attention and has been research hotspots of limnology around the world.
Among the 1482 institutions that participated in the Lake Taihu research, the Chinese Academy of Sciences led institutional productivity with 812 papers, followed by Nanjing University with 183, Hohai University with 118, and Chinese Research Academy of Environmental Sciences with 92. Within the Chinese Academy of Sciences, Nanjing Institute of Geography and Limnology, Institute of Hydrobiology, and Institute of Soil Science were the top 3 productive sub-institutions, with 366,74 , and 74 papers, respectively.

Author productivity analysis revealed that a small group of productive authors contributed a large number of publications about Lake Taihu research. Among the 3080 authors who (co)authored at least one Lake Taihu paper, 2956 (96.0\%) contributed less than 10 papers. The most productive authors of Lake Taihu research were Qin BQ and Zhang YL, with 106 and 64 articles, respectively. Other prolific authors included Zhu GW, with 56 papers; Kong FX, with 51; and Zhang Y, with 51 .

\section{Research hotspots: author keywords}

Because our bibliometric analysis focused on certain lakes and because the lake names were used as our search terms, the lake name (Lake Taihu, Lake Baikal, Lake Biwa, Lake Erie, Lake Michigan, Lake Ontario, Lake Superior, and Lake Victoria) was undoubtedly the most frequently used keyword. However, the lake name cannot represent the research hotspot; thus, we excluded the lake name as the most frequently used

Table 1 Exponential model of total publication number and increase rate of total publication number vs year of eight hot lakes (Lake Baikal, Lake Biwa, Lake Erie, Lake Michigan, Lake Ontario, Lake Superior, Lake Victoria, and Lake Taihu) from 1996 to 2015

\begin{tabular}{|c|c|c|c|c|c|c|c|}
\hline Lake name & Increase rate & $r^{2}$ & $\begin{array}{l}p \\
\text { value }\end{array}$ & Lake name & Increase rate & $r^{2}$ & $\begin{array}{l}p \\
\text { value }\end{array}$ \\
\hline Lake Baikal & 0.030 & 0.635 & 0.000 & Lake Ontario & 0.019 & 0.320 & 0.009 \\
\hline Lake Biwa & 0.031 & 0.495 & 0.001 & Lake Superior & 0.027 & 0.443 & 0.001 \\
\hline Lake Erie & 0.031 & 0.604 & 0.000 & Lake Victoria & 0.089 & 0.889 & 0.000 \\
\hline Lake Michigan & 0.025 & 0.646 & 0.000 & Lake Taihu & 0.268 & 0.929 & 0.000 \\
\hline
\end{tabular}


Table 2 Distributions of the subject categories

\begin{tabular}{llll}
\hline SCI subject category in 2015 & TPN (\%) & SCI subject category in 2015 & TPN (\%) \\
\hline Environmental Sciences Ecology & $863(56.0 \%)$ & Biotechnology Applied Microbiology & $55(3.6 \%)$ \\
Marine Freshwater Biology & $278(18.0 \%)$ & Chemistry & $53(3.4 \%)$ \\
Engineering & $228(14.8 \%)$ & Science Technology Other Topics & $47(3.0 \%)$ \\
Water Resources & $176(11.4 \%)$ & Oceanography & $43(2.8 \%)$ \\
Geology & $121(7.8 \%)$ & Physical Geography & $37(2.4 \%)$ \\
Agriculture & $88(5.7 \%)$ & Biochemistry Molecular Biology & $34(2.2 \%)$ \\
Toxicology & $76(4.9 \%)$ & Meteorology Atmospheric Sciences & $31(2.0 \%)$ \\
Remote Sensing & $73(4.7 \%)$ & Spectroscopy & $26(1.7 \%)$ \\
Microbiology & $69(4.5 \%)$ & Public, Environmental and Occupational Health & $18(1.2 \%)$ \\
Imaging Science Photographic Technology & $57(3.7 \%)$ & Fisheries & $17(1.1 \%)$ \\
\hline
\end{tabular}

$T P N$ total publication number, percentage $(\%)$ percentage of total publications for a certain subject category.

keyword in the keyword analysis. We present the 20 most frequently used keywords of Lake Taihu research within each of the 5-year intervals to guarantee a reasonable time-span and to minimize year-to-year fluctuations during 1996-2015 in Table 4 after excluding the lake name.

During the period from 1996 to 2015, "sediment" was the most frequently used word, ranking first in the author keyword analysis (Table 4). Lake sediments act as a balance of source and sink for nutrients and for a variety of environmental contaminants. Sediment supports critical ecological services by providing abundant benthic community habitats. In addition, fertile sediment plays a positive role in the growth, development, reproduction, and germination of aquatic vegetation. Lake sediments register a large amount of environmental and ecological information far beyond the lake itself. Therefore, sediment was the most important issue in Lake Taihu pollution and environmental research from 1996 to 2015. The keywords "eutrophication", "Microcystis aeruginosa", "cyanobacterial blooms", and "remote sensing" ranked second to fifth in the author keyword analysis, respectively, from 1996 to 2015 (Table 4). Therefore, the research focused on eutrophication causes and control, the physiology and ecology of Microcystis aeruginosa, cyanobacterial blooms, and remote sensing technique application has been the hotspots of Lake Taihu research during 1996-2015. It is easily understandable that these keywords have been the top five frequently used keywords because Lake Taihu faces serious eutrophication and cyanobacterial bloom outbreaks and because Lake Taihu is a large lake, thus providing convenient application of remote sensing technology in Lake Taihu research. In addition, the environmental effects of heavy metal, microcystin, and organochlorine pesticides have become a primary focus of Lake Taihu research (Table 4).
Within each of the 5-year intervals, the rank of keywords changed greatly, which partially reflected the change in research hotspots. During the period from 1996 to 2000,19 articles were published with too few keywords; thus, identifying the research hotspots is difficult and uncertain. We only compared the change in the keywords of three periods (2001-2005, 2006-2010, and 2011-2015). We found that sediment, eutrophication, "phosphorus," and M. aeruginosa were the most frequently used keywords and appeared in the top 10 keywords during all three periods (Table 4). However, the ranks of sediment, eutrophication, and phosphorus slightly decreased, while the rank of $M$. aeruginosa gradually increased from 2001-2005 to 2006-2010 and further increased to 2011-2015 (Table 4). During the period from 2011 to 2015 , cyanobacterial blooms ranked first of all keywords, and the rank of remote sensing rapidly increased, reflecting the wide use of new technologies, such as remote sensing, to monitor and study cyanobacterial blooms. Although the ranks of sediment, eutrophication, and phosphorus slightly decreased, nutrient-related and eutrophication research remained vigorous during the period from 2011 to 2015 and is predicted to remain a primary research emphasis in the near future. In addition, we note that "climate change" has ranked 20th during the period from 2011 to 2015, reflecting the greater attention given to the effect of climate change on cyanobacterial blooms in the past 5 years.

A comparison of keywords used during the period from 1996 to 2015 for eight hot research lakes around the world showed some common research hotspots and some significant differences (Tables 4 and 5). Of all the eight hot lakes, sediment was one of the top five frequently used keywords in seven lakes, excluding Lake Victoria. The most frequently used keywords of eight 
Table 3 Top 20 most productive journals (1996-2015) with total publication number (TPN), impact fact (IF), h-index, ISI journal category, and the journal position in its category.

\begin{tabular}{|c|c|c|c|c|}
\hline Journal title & TPN (\%) & Subject category (position) & IF (R) in 2015 & h-index \\
\hline Journal of Environmental Sciences China & $70(4.54 \%)$ & Environmental Sciences $(98 / 223)$ & $2.002(11)$ & 16 \\
\hline Hydrobiologia & $60(3.89 \%)$ & Marine Freshwater Biology (25/103) & $2.275(10)$ & 20 \\
\hline Environmental Science and Pollution Research & $50(3.24 \%)$ & Environmental Sciences (54/223) & $2.828(7)$ & 9 \\
\hline Chemosphere & $48(3.11 \%)$ & Environmental Sciences (223/39) & $3.340(5)$ & 21 \\
\hline Ecological Engineering & $48(3.11 \%)$ & $\begin{array}{l}\text { Ecology }(55 / 145) \\
\text { Engineering, Environmental (17/47) } \\
\text { Environmental Sciences }(67 / 223)\end{array}$ & $2.580(9)$ & 15 \\
\hline Environmental Monitoring and Assessment & $44(2.85 \%)$ & Environmental Sciences (110/223) & $1.679(13)$ & 13 \\
\hline Fresenius Environmental Bulletin & $35(2.27 \%)$ & Environmental Sciences $(219 / 223)$ & $0.378(19)$ & 4 \\
\hline Science of the Total Environment & $34(2.20 \%)$ & Environmental Sciences (18/223) & $4.099(4)$ & 13 \\
\hline Environmental Earth Sciences & $31(2.01 \%)$ & $\begin{array}{l}\text { Environmental Sciences }(105 / 223) \\
\text { Water Resources }(26 / 83)\end{array}$ & $1.765(12)$ & 8 \\
\hline Journal of Freshwater Ecology & $31(2.01 \%)$ & $\begin{array}{l}\text { Ecology }(125 / 145) \\
\text { Limnology }(20 / 20)\end{array}$ & $0.650(18)$ & 6 \\
\hline Environmental Science and Technology & $28(1.82 \%)$ & $\begin{array}{l}\text { Environmental Sciences (10/223) } \\
\text { Engineering, Environmental (3/47) }\end{array}$ & $5.330(2)$ & 15 \\
\hline PLOS One & $27(1.75 \%)$ & Multidisciplinary Sciences $(9 / 57)$ & $3.234(6)$ & 7 \\
\hline Spectroscopy and Spectral Analysis & $23(1.49 \%)$ & Spectroscopy (44/44) & $0.292(20)$ & 2 \\
\hline Environmental Pollution & $22(1.43 \%)$ & Environmental Sciences (17/223) & $4.143(3)$ & 13 \\
\hline Pedosphere & $21(1.36 \%)$ & Soil Science $(16 / 34)$ & $1.500(15)$ & 13 \\
\hline Water Research & $19(1.23 \%)$ & $\begin{array}{l}\text { Environmental Sciences }(9 / 223) \\
\text { Engineering, Environmental }(2 / 47) \\
\text { Water Resources }(1 / 83)\end{array}$ & $5.528(1)$ & 12 \\
\hline Science China-Earth Sciences & $19(1.23 \%)$ & Geosciences, Multidisciplinary $(97 / 175)$ & $1.491(16)$ & 9 \\
\hline International Journal of Remote Sensing & $17(1.10 \%)$ & $\begin{array}{l}\text { Remote Sensing }(13 / 28) \\
\text { Imaging Science and Photographic Technology }(9 / 24)\end{array}$ & $1.652(14)$ & 6 \\
\hline Ecotoxicology & $16(1.04 \%)$ & $\begin{array}{l}\text { Ecology }(48 / 145) \\
\text { Environmental Sciences }(60 / 223) \\
\text { Toxicology }(37 / 88)\end{array}$ & $2.706(8)$ & 7 \\
\hline Chinese Journal of Oceanology and Limnology & $16(1.04 \%)$ & $\begin{array}{l}\text { Limnology }(19 / 20) \\
\text { Oceanography }(51 / 61)\end{array}$ & $0.657(17)$ & 5 \\
\hline
\end{tabular}

$T P N$ total publication number, percentage $(\%$ percentage of publications for a certain journal, $I F$ impact factor, and $R$ rank

lakes were "phytoplankton" and climate change. These keyword results indicated that sediment, phytoplankton, and climate change were the common, most active research issues of the eight lakes. In addition, eutrophication and cyanobacterial blooms were the most frequently used keywords in the Lake Taihu, Lake Biwa, and Lake Erie research. For example, similar drinking crises and water supply shutdowns were caused by harmful cyanobacterial blooms that broke out in 2007 and 2014 (Paerl et al. 2014, Qin et al. 2010). For Lake Baikal, palaeolimnology and sedimentary records (diatoms, paleoclimate, Holocene) were the most active fields. In the Great Lakes (Lake Erie, Lake Michigan, Lake Ontario, Lake Superior), refractory organic compounds (e.g., PCBs, PAHs) and biological invasion (invasive species, zebra mussel) became more active research issues. In Lake Victoria, fishery (cichlids, fish, Nile perch) was the most active field.

\section{Future research directions}

\section{Environmental effects of physical processes}

Although the keywords seldom mentioned physical processes, such as wind waves or light attenuation, it is well known that physical processes, especially wind waves, play a vital role in lake ecosystem evolution for large shallow lakes. Actually, the widely used author keywords sediment and "shallow lake" is highly linked to environmental effects of physical processes. In previous decades, the effects of wind waves on sediment resuspension, underwater light availability, and nutrient release have been elucidated based on long-term site-specific observations, multidisciplinary combined high-frequency monitoring, large-scale in situ control experiments, and long-term remote sensing estimation (Liu et al. 2014, Liu et al. 2013, Qin et al. 2004, Shi et al. 2015, Zhang et al. 2006). However, it is still difficult to find the intrinsic linkage between wind 


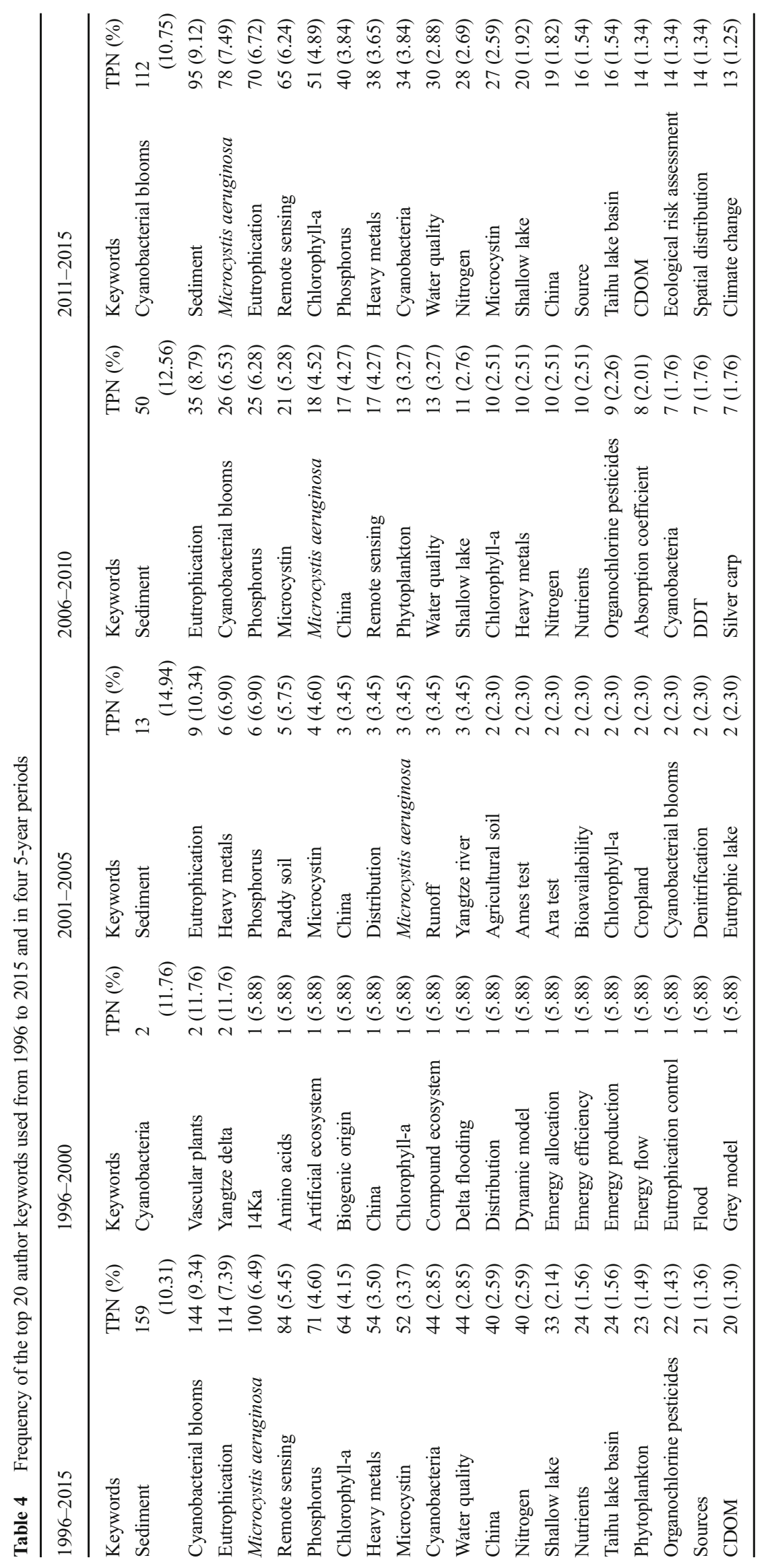


Table 5 Frequency of the top 20 author keywords used from 1996 to 2015 in other seven hot lakes (Lake Baikal, Lake Biwa, Lake Erie, Lake Michigan, Lake Ontario, Lake Superior, and Lake Victoria)

\begin{tabular}{|c|c|c|c|c|c|c|c|}
\hline Rank & Lake Baikal & Lake Biwa & Lake Erie & $\begin{array}{l}\text { Lake } \\
\text { Michigan }\end{array}$ & Lake Ontario & Lake Superior & Lake Victoria \\
\hline 1 & Sediment & Sediment & Great Lakes & Great Lakes & Great Lakes & Great Lakes & Cichlid \\
\hline 2 & Diatoms & Japan & Zebra mussel & PCBs & PCBs & Lake trout & Fish \\
\hline 3 & Climate change & Bluegill & Invasive species & PAHs & Bioaccumulation & PCBs & Uganda \\
\hline 4 & Siberia & Ayu & Dreissena & $\begin{array}{l}\text { Invasive } \\
\text { species }\end{array}$ & Sediment & Sediment & East Africa \\
\hline 5 & Paleoclimate & Stable isotopes & Sediment & Sediment & Zebra mussel & Lake level & Nile perch \\
\hline 6 & Taxonomy & $\begin{array}{l}\text { Dissolved organic } \\
\text { matter }\end{array}$ & $\begin{array}{l}\text { Dreissena } \\
\text { polymorpha }\end{array}$ & Zooplankton & Fish & Water quality & Speciation \\
\hline 7 & Baikal rift & Phytoplankton & PCBs & Zebra mussel & Invasive species & Fish & Kenya \\
\hline 8 & Holocene & Taxonomy & Phytoplankton & Water quality & Mercury & Mercury & Africa \\
\hline 9 & Phytoplankton & Cyanobacteria & $\begin{array}{l}\text { Microcystis } \\
\quad \text { aeruginosa }\end{array}$ & Food web & Lake trout & Sea lamprey & Schistosoma manson \\
\hline 10 & Russia & $\begin{array}{l}\text { Dissolved organic } \\
\text { carbon }\end{array}$ & Cyanobacteria & Fish & Dreissena & Lake herring & Tanzania \\
\hline 11 & $\begin{array}{l}\text { Neutrino } \\
\text { telescopes }\end{array}$ & Plecoglossus altivelis & Water quality & Green bay & $\begin{array}{l}\text { Hamilton } \\
\text { Harbour }\end{array}$ & $\begin{array}{l}\text { Remote } \\
\text { sensing }\end{array}$ & Climate change \\
\hline 12 & Morphology & 2-methylisoborneol & Phosphorus & Round goby & Water quality & $\begin{array}{l}\text { Stable } \\
\text { isotopes }\end{array}$ & Eutrophication \\
\hline 13 & $16 \mathrm{~s}$ rRNA & Climate change & Round goby & Lake level & Reproduction & Food web & Wetlands \\
\hline 14 & Amphipods & Dioxins & Eutrophication & Yellow perch & Food web & $\begin{array}{l}\text { Climate } \\
\text { change }\end{array}$ & Sexual selection \\
\hline 15 & Endemism & Eutrophication & Modeling & Dry deposition & Model & Phosphorus & Lake Victoria basin \\
\hline 16 & New species & Fluorescence & Walleye & Lake trout & Phytoplankton & Nutrients & $\begin{array}{l}\text { Haplochromine } \\
\text { cichlids }\end{array}$ \\
\hline 17 & Gas hydrates & Geosmin & Remote sensing & $\begin{array}{l}\text { Climate } \\
\text { change }\end{array}$ & $\begin{array}{l}\text { St. Lawrence } \\
\text { river }\end{array}$ & Toxaphene & Heavy metals \\
\hline 18 & Pleistocene & Mitochondrial DNA & $\begin{array}{l}\text { Cyanobacterial } \\
\text { blooms }\end{array}$ & Predation & Zooplankton & Zooplankton & Mate choice \\
\hline 19 & Thermal bar & Morphology & Wetlands & Mercury & Nearshore & Phytoplankton & Water quality \\
\hline 20 & Biogenic silica & Pesticide & Chlorophyll-a & Phosphorus & Phosphorus & Diporeia & Adaptive radiation \\
\hline
\end{tabular}

waves and cyanobacterial bloom outbreaks, lake ecosystem responses, and feedback. Future studies need to answer at least the following three questions: (1) What are the influential mechanisms and critical field thresholds of wind waves on a specific cyanobacterial bloom, although the experimental effect processes of hydrodynamic force on the formation of cyanobacterial blooms are clear? (2) How do wind waves affect macrophyte degradation through direct damage or uprooting and through indirect effects on light availability and macrophyte photosynthesis? (3) How do wind waves affect the redox potential of the water-sediment interface through oxygen enrichment and further affect the microbial composition, organic matter degradation and mineralization, and nutrient cycles to support phytoplankton and cyanobacterial blooms?

\section{Nutrient cycles and control and ecosystem responses}

Excessive pollutants (heavy metals, organochlorine pesticides) and nutrient (nitrogen and phosphorus) inputs from industrialization, urbanization, and intensive agriculture are highly linked to harmful cyanobacteria proliferation and to water quality deterioration (Davis et al. 2009, Qin et al. 2010). Therefore, many studies have focused on the sources, cycle, transformation, and fate of pollutants and nutrients in water and sediment in Lake Taihu in previous decades (Table 4). The widely used author keywords sediment, cyanobacterial blooms, eutrophication, phosphorus, and "nitrogen" are highly linked to this study direction. Although a rough proportion of external and internal nutrients, the basic approaches of nutrient cycles, and nutrient reduction targets have been clarified (Qin et al. 2013, Xu et al. 2014), lake ecosystem responses, feedback mechanisms of nutrient enrichment and reduction, and seasonal differences are still unsolved. Therefore, future studies will focus on the following four aspects: (1) the mechanism of nutrient cycling in the presence of microorganisms under hydrodynamic interactions; (2) phytoplankton biomass and community composition response mechanism to nutrient enrichment and reduction; (3) succession mechanism of the lake ecosystem to nutrient 
enrichment and reduction; and (4) nutrient criteria, control targets and feasible control measurements to alleviate and eliminate harmful cyanobacteria blooms in Lake Taihu.

\section{Cyanobacteria bloom monitoring, causes, forecast, and management}

Frequent harmful cyanobacteria blooms and attendant disaster events have seriously endangered drinking water safety; public health; tourism and fisheries development; and ecosystem structure, function and services in Lake Taihu in previous decades. Therefore, cyanobacteria bloom has become the most frequently used keyword in Lake Taihu research which ranked first in the past 5 years (2011-2015) (Table 4). This research has led to the development of many new technologies and approaches for monitoring, determining causes, forecasting, early warning, and managing harmful cyanobacteria blooms. For example, remote sensing and high frequency monitoring have been widely used to monitor the formation and development and map the spatiotemporal pattern, migration, and accumulation of harmful cyanobacteria blooms (Duan et al. 2009, Hu et al. 2010, Zhu et al. 2014). Therefore, remote sensing ranked fifth of all author keyword in the past 5 years (2011-2015) (Table 3). A large-scale integrated monitoring, forecasting, and warning system was developed, and a series of emergency response measures were instigated based on early warning to mitigate cyanobacterial bloom pollution risk ( $\mathrm{Li}$ et al. 2014, Qin et al. 2015). However, there are still many scientific and technical questions that need to be resolved in future studies. The undersampling of cyanobacterial blooms needs to be improved because of the large spatial and temporal scales over which they occur and because of the cloudy and rainy weather, which limits the availability of remote sensing images. Highfrequency observation of meteorological factors, physical indicators, and partial water quality parameters should be used to resolve the minute-hour temporal scale dynamic process (Liu et al. 2014, Zhu et al. 2014). Alternative approaches for monitoring and calculating the HAB biomass of the whole water column should be developed by combining remote sensing, a vertical distribution model, and other technological advances. Phytoplankton biomass predictive models and three-dimensional hydrodynamic models need to be better coupled to nutrient cycles, phytoplankton growth and succession, and ecosystem-level models to form complex ecosystem models for cyanobacterial bloom forecasting. In addition, incorporation of toxicology (microcystin) and social science into cyanobacterial bloom risk and management research should be a firm goal of Lake Taihu research, enabling a more comprehensive assessment and management of the impact of cyanobacterial blooms on human wellbeing (e.g., cultural, economic, human health).

\section{Eutrophication and climate change interactions}

Many hypotheses and case studies have shown that harmful cyanobacteria blooms are predicted to increase due to eutrophication and climate change (O'neil et al. 2012, Paerl and Paul 2012, Rigosi et al. 2014). In the past 10 years, some studies have shown that climate warming greatly affects harmful cyanobacteria blooms, including an earlier initial blooming date, lengthened annual duration, and substantial increases in the occurrence of cyanobacteria blooms in Lake Taihu (Deng et al. 2014a, Duan et al. 2009, Zhang et al. 2012). In addition, nutrient availability is considered to exert a stronger control than water temperature on phytoplankton communities during spring, and phytoplankton community composition was mediated by nutrient concentrations, but this effect was strongly enhanced by elevated water temperatures (Deng et al. 2014b). However, the detailed relative contribution and interaction of climate warming and increased eutrophication in determining harmful cyanobacterial blooms are largely unclear. Therefore, future studies need to answer at least four questions: (1) Which factor, nutrients (nitrogen and phosphorus) or water temperature, is most important for controlling phytoplankton biomass and community composition? What is the seasonal difference for these two factors? (2) Do nutrients and water temperature interact to promote cyanobacterial blooms and is there a synergistic interaction? (3) Does the interaction between nutrient enrichment and climate warming vary with cyanobacterial taxa composition and season? (4) What are the management strategies and technique approaches to mitigate the effects of human nutrient enrichment and climate warming on harmful cyanobacteria?

\section{Ecosystem degradation mechanism and ecological practice of lake restoration}

Since the mid-1990s, macrophyte restoration has been proposed and widely promoted as an affordable ecological solution to control lake eutrophication and to improve water quality based on an alternate stable state theory developed in small shallow lakes (Schefer 1998, Scheffer et al. 1993). However, a large-scale ecological engineering experiment conducted in the large, shallow, eutrophic Lake Taihu, China, from 2003 to 2006 was proven unsuccessful (Qin 2013). The concepts of how organism groups respond to nutrient reduction and ecological restoration measures are clear in small shallow lakes. However, it is more difficult to understand these concepts for large shallow lakes, which are highly affected by sediment resuspension induced by frequent wind waves. Sediment resuspension can deteriorate light availability for macrophyte restoration and result in a new equilibrium for nutrients although external nutrient loading is reduced (Jeppesen et al. 2005, Liu etal. 2013). Of course, the failure is generally linked to insufficient or no decrease in the autochthonous or in-lake nutrient loadings, the unadjusted fish community, and accumulated algal scum. Therefore, since the late 2000 s, the recovery strategy in 
Lake Taihu has changed from macrophyte restoration to pollution source control (Qin 2013). No specific author keyword about lake ecological restoration ranked the top 20 author keywords from 1996 to 2015. However, in the future, additional studies should be focused on ecosystem degradation mechanisms, and the thresholds of environment factors for ecological restoration, including nutrients, light availability, and fish predation, should be clarified (Zhang et al. 2016). Once the nutrients are reduced to a very low level and environmental conditions inhibiting macrophyte restoration are highly improved, ecological practice of lake restoration should be carried out in some local waters with favorable habitat conditions in Lake Taihu. In addition, it will be possible to develop more enduring strategies for greater sustainable ecosystem restoration for Lake Taihu. Of course, we cannot expect Lake Taihu to fully recover within 15 or 30 years even longer time.

\section{Conclusion}

In this study, we provide an alternative perspective on Lake Taihu research trends by performing a comparative quantitative and qualitative analysis of development, current hotspots, and future directions of Lake Taihu research using a bibliometric analysis of eight hot research lakes. Our study suggests that there has been rapid growth in the scientific outputs in Lake Taihu research in the past 20 years compared with other hot research lakes around the world. The results indicated that the Journal of Environmental Sciences China was the most active journal. The results also revealed that Environmental Sciences Ecology, Marine Freshwater Biology, and Engineering were the three top popular subject categories. Nanjing Institute of Geography and Limnology was the most productive institution for the total number of articles, and Qin BQ was the most productive author. Keyword analysis obviously indicated that sediment and cyanobacterial blooms were the most active research issues and that remote sensing was the most widely used new technique in the studied period. In addition, the environmental effects of heavy metal, microcystin, and organochlorine pesticides have become a primary focus of Lake Taihu research.

Based on the keyword analysis and considering the present environmental problems of Lake Taihu, additional studies should be focused on the following five aspects: (1) environmental effects of physical processes; (2) nutrient cycles and control and ecosystem responses; (3) cyanobacteria bloom monitoring, causes, forecast, and management; (4) eutrophication and climate change interactions; and (5) ecosystem degradation mechanisms and ecological practice of lake restoration.

Acknowledgements This study was jointly funded by the National Natural Science Foundation of China (grants 41325001, 41230744, and 41271355) and the Major Projects on Control and Rectification of Water Body Pollution (2012ZX07101-010).

\section{References}

The World Bank TW (2010) Water pollution emergencies in China: prevention and response

Barbosa FG, Schneck F (2015) Characteristics of the top-cited papers in species distribution predictive models. Ecol Model 313:77-83

Davis TW, Berry DL, Boyer GL, Gobler CJ (2009) The effects of temperature and nutrients on the growth and dynamics of toxic and nontoxic strains of Microcystis during cyanobacteria blooms. Harmful Algae 8:715-725

Deng J, Qin B, Paerl HW, Zhang Y, Ma J, Chen Y (2014a) Earlier and warmer springs increase cyanobacterial (Microcystis spp.) blooms in subtropical Lake Taihu, China. Freshw Biol 59:1076-1085

Deng J, Qin B, Paerl HW, Zhang Y, Wu P, Ma J, Chen Y (2014b) Effects of nutrients, temperature and their interactions on spring phytoplankton community succession in Lake Taihu, China. PLoS One 9, e113960

Duan H, Ma R, Xu X, Kong F, Zhang S, Kong W, Hao J, Shang L (2009) Two-decade reconstruction of algal blooms in China's Lake Taihu. Environ Sci Technol 43:3522-3528

Fan C (2015) Progress and prospect in formation of black bloom in Lake Taihu: a review. J Lake Sci 27:553-566

Gao W, Chen Y, Liu Y, Guo H-c (2015) Scientometric analysis of phosphorus research in eutrophic lakes. Scientometrics 102:1951-1964

Guo L (2007) Doing battle with the green monster of Taihu Lake. Science 317:1166-1166

Hirsch JE (2005) An index to quantify an individual's scientific research output. Proc Natl Acad Sci U S A 102:16569-16572

Hu C, Lee Z, Ma R, Yu K, Li D, Shang S (2010) Moderate resolution imaging spectroradiometer (MODIS) observations of cyanobacteria blooms in Taihu Lake, China. J Geophys Res Oceans 1978-2012: 115. doi:10.1029/2009JC005511

Jeppesen E, Søndergaard M, Jensen JP, Havens KE, Anneville O, Carvalho L, Coveney MF, Deneke R, Dokulil MT, Foy B (2005) Lake responses to reduced nutrient loading-an analysis of contemporary long-term data from 35 case studies. Freshw Biol 50:1747-1771

Khan MA, Ho Y-S (2012) Top-cited articles in environmental sciences: merits and demerits of citation analysis. Sci Total Environ 431:122127

Kong F, Ma R, Gao J, Wu X (2009) The theory and practice of prevention, forecast and warning on cyanobacteria bloom in Lake Taihu. J Lake Sci 21:314-328

Li J, Wang M-H, Ho Y-S (2011) Trends in research on global climate change: a Science Citation Index Expanded-based analysis. Glob Planet Chang 77:13-20

Li W, Qin B, Zhu G (2014) Forecasting short-term cyanobacterial blooms in Lake Taihu, China, using a coupled hydrodynamic-algal biomass model. Ecohydrology 7:794-802

Liu X, Zhang Y, Yin Y, Wang M, Qin B (2013) Wind and submerged aquatic vegetation influence bio-optical properties in large shallow Lake Taihu, China. J Geophys Res Biogeosci 118:713-727

Liu X, Zhang Y, Wang M, Zhou Y (2014) High-frequency optical measurements in shallow Lake Taihu, China: determining the relationships between hydrodynamic processes and inherent optical properties. Hydrobiologia 724:187-201

O'neil J, Davis TW, Burford MA, Gobler C (2012) The rise of harmful cyanobacteria blooms: the potential roles of eutrophication and climate change. Harmful Algae 14:313-334

Paerl HW, Paul VJ (2012) Climate change: links to global expansion of harmful cyanobacteria. Water Res 46:1349-1363

Paerl HW, Gardner WS, McCarthy MJ, Peierls BL, Wilhelm SW (2014) Algal blooms: noteworthy nitrogen. Science 346:175

Pasgaard M, Strange N (2013) A quantitative analysis of the causes of the global climate change research distribution. Glob Environ Chang 23:1684-1693 
Pritchard A (1969): Statistical bibliography or bibliometrics? Journal of Documentation, 348-349

Qin B, Hu W, Gao G, Luo L, Zhang J (2004) Dynamics of sediment resuspension and the conceptual schema of nutrient release in the large shallow Lake Taihu, China. Chin Sci Bull 49:54-64

Qin B, Xu P, Wu Q, Luo L, Zhang Y (2007) Environmental issues of Lake Taihu, China. Hydrobiologia 581:3-14

Qin B (2009a) Lake eutrophication: control countermeasures and recycling exploitation. Ecol Eng 35:1569-1573

Qin B (2009b) Progress and prospect on the eco-environmental research of Lake Taihu. J Lake Sci 21:445-455

Qin B, Zhu G, Gao G, Zhang Y, Li W, Paerl HW, Carmichael WW (2010) A drinking water crisis in Lake Taihu, China: linkage to climatic variability and lake management. Environ Manag 45:105-112

Qin B (2013) A large-scale biological control experiment to improve water quality in eutrophic Lake Taihu, China. Lake Reservoir Manage 29:33-46

Qin B, Gao G, Zhu G, Zhang Y, Song Y, Tang X, Xu H, Deng J (2013) Lake eutrophication and its ecosystem response. Chin Sci Bull 58: 961-970

Qin B, Li W, Zhu G, Zhang Y, Wu T, Gao G (2015) Cyanobacterial bloom management through integrated monitoring and forecasting in large shallow eutrophic Lake Taihu (China). J Hazard Mater 287:356-363

Rigosi A, Carey CC, Ibelings BW, Brookes JD (2014) The interaction between climate warming and eutrophication to promote cyanobacteria is dependent on trophic state and varies among taxa. Limnol Oceanogr 59:99-114

Schefer M (1998) Ecology of shallow lakes. Kluwer Academic Publishers, Netherlands, Dordretcht

Scheffer M, Hosper S, Meijer M, Moss B, Jeppesen E (1993) Alternative equilibria in shallow lakes. Trends Ecol Evol 8:275-279

Shi K, Zhang Y, Zhu G, Liu X, Zhou Y, Xu H, Qin B (2015) Long-term remote monitoring of total suspended matter concentration in Lake Taihu using $250 \mathrm{~m}$ MODIS-Aqua data. Remote Sens Environ 164: 43-56

Tan J, Fu H-Z, Ho Y-S (2014) A bibliometric analysis of research on proteomics in Science Citation Index Expanded. Scientometrics 98:1473-1490

TBA-MWR (2015) Taihu basin \& southeast rivers water resources bulletin: 2014., pp 1-28

Wang L, Chen X, Bao A, Zhang X, Wu M, Hao Y, He J (2015) A bibliometric analysis of research on Central Asia during 1990 2014. Scientometrics 105:1223-1237
Xu H, Paerl HW, Qin B, Zhu G, Gao G (2010) Nitrogen and phosphorus inputs control phytoplankton growth in eutrophic Lake Taihu, China. Limnol Oceanogr 55:420-432

Xu H, Paerl HW, Qin B, Zhu G, Hall N, Wu Y (2014) Determining critical nutrient thresholds needed to control harmful cyanobacterial blooms in eutrophic Lake Taihu, China. Environ Sci Technol 49: 1051-1059

Yang M, Yu J, Li Z, Guo Z, Burch M, Lin T-F (2008) Taihu Lake not to blame for Wuxi's woes. Science 319:158-158

Zhang L, Wang M-H, Hu J, Ho Y-S (2010a) A review of published wetland research, 1991-2008: ecological engineering and ecosystem restoration. Ecol Eng 36:973-980

Zhang M, Duan H, Shi X, Yu Y, Kong F (2012)Contributions of meteorology to the phenology of cyanobacterial blooms: implications for future climate change. Water Res 46:442-452

Zhang X, Chen C, Ding J, Hou A, Li Y, Niu Z, Su X, Xu Y, Laws EA (2010b) The 2007 water crisis in Wuxi, China: analysis of the origin. J Hazard Mater 182:130-135

Zhang Y, Qin B, Zhu G, Gao G, Luo L, Chen W (2006) Effect of sediment resuspension on underwater light field in shallow lakes in the middle and lower reaches of the Yangtze River: a case study in Longgan Lake and Taihu Lake. Sci China Ser D 49:114-125

Zhang Y, van Dijk MA, Liu M, Zhu G, Qin B (2009) The contribution of phytoplankton degradation to chromophoric dissolved organic matter (CDOM) in eutrophic shallow lakes: field and experimental evidence. Water Res 43:4685-4697

Zhang Y, Liu X, QIn B, Shi K, Deng J, Zhou Y (2016): Aquatic vegetation in response to increased eutrophication and degraded light climate in Eastern Lake Taihu Implications for lake ecological restoration. Scientific Reports 6, doi:10.1038/srep23867

Zhi W, Ji G (2012) Constructed wetlands, 1991-2011: a review of research development, current trends, and future directions. Sci Total Environ 441:19-27

Zhi W, Yuan L, Ji G, Liu Y, Cai Z, Chen X (2015) A bibliometric review on carbon cycling research during 1993-2013. Environ Earth Sci 74:6065-6075

Zhu M, Paerl HW, Zhu G, Wu T, Li W, Shi K, Zhao L, Zhang Y, Qin B, Caruso AM (2014) The role of tropical cyclones in stimulating cyanobacterial (Microcystis spp.) blooms in hypertrophic Lake Taihu, China. Harmful Algae 39:310-321 